\title{
ADRENAL ONCOCYTOMA IN CHILDREN - CASE REPORT
}

\author{
Nikola Y. Kolev ${ }^{1}$, Valentin L. Ignatov ${ }^{1}$, Anton Y. Tonev ${ }^{1}$, Aleksandar K. Zlatarov ${ }^{1}$, \\ Elitsa P. Encheva ${ }^{2}$, Tanya N. Kirilova ${ }^{1}$, Vasil M. Bojkov ${ }^{3}, K_{\text {Krasimir D. Ivanov }}{ }^{1}$ \\ 1) Department of General and Operative Surgery, \\ 2) Department of Nuclear Medicine, Metabolic Therapy and Radiotherapy, \\ 3) Department of Surgical Diseases, \\ University Hospital "St. Marina" Varna, Medical University of Varna, Bulgaria.
}

\begin{abstract}
Adrenal oncocytomas are usually non functional and hence incidentally detected. Most of these adrenal neoplasms are benign. Functioning adrenocortical oncocytomas are extremely rare and most reported patients are between 40 and 60 years of age. We found in the literature that only several cases of functioning adrenocortical oncocytomas have been reported in childhood. We report a case of functioning adrenocortical oncocytoma in a 9 years old female child presenting with virilization. She presented with deepening of the voice and excessive hair growth, and elevation of plasma testosterone and dehydroepiandrosterone sulfate. We presented adiscussion of this case, successfully managed by laparoscopic surgery.
\end{abstract}

Key words: oncocytoma, adrenal neoplasma, virilization, laparoscopic surgery, adrenocortical neoplasma.

\section{INTRODUCTION}

Oncocytoma is a tumor that is composite predominantly of polygonal oncocytes with abundant granular and intensely eosinophilic cytoplasm. The term "oncocyte", first used by Hamperl ${ }^{2}$ in 1950, describes large, highly eosinophilic, granular cells associated with a hurthle cell tumor of the thyroid gland. It may occurs in every organ, most commonly the kidney, salivary glands, and thyroid, parathyroid, lung, pituitary gland and ovary ${ }^{1,3}$. An oncocytoma that appears in the adrenal gland is very rare and usually benign and nonfunctioning ${ }^{3}$. Because of the unusual occurrence of functioning adrenocortical oncocytoma, we report these case of adrenocortical oncocytoma in a girl presenting with virilization.

\section{CASE REPORT}

A 9 years old girl presented with deepening of the voice and excessive hair growth as well as changein body habitus since about a half year prior to admission. She was born at full term without perinatal problems, often suffering from respiratory infections. Her body weight was $34.7 \mathrm{~kg}$, height was $144 \mathrm{~cm}$ and body mass index was $16.88 \mathrm{~kg} / \mathrm{m}^{2}$. Her blood pressure was normal. Physical examination revealed acne on the face and a male pattern of excessive hair on the chin, and the limbs. Her breast was Tanner stage 1. She had mild clitoromegaly.

\section{Laboratory and imaging constellations}

We performed a hormonal study for evaluation of virilization, which revealed increased plasma testosterone (15.4-17.8-26nmol/1, reference range: $0.5-2.6 \mathrm{nmol} / 1)$, free testosterone $(0.263 \mathrm{nmol} / 1$, reference range: $0.003-0.03 \mathrm{nmol} /$ 1) and and dehydroepiandrosterone sulfate (DHEA-S) (14.7umol/l, reference range: 0.95-11.67umol/l)levels. Plasma thyroid-stimulating hormone (TSH) was $4.054 \mathrm{uIU} / \mathrm{ml}$ (reference range: $0.55-4.78 \mathrm{uIU} / \mathrm{ml}$ ) and plasma cortisol rhythm was $48.22 \mathrm{nmol} / 1$ and $75.16 \mathrm{nmol} / 1$ (reference range: $118.6-$ $618 \mathrm{nmol} / 1$ at $8 \mathrm{~h}$ and $50-150 \mathrm{nmol} / \mathrm{l}$ at $22 \mathrm{~h}$ ). The abdominal computer tomography (CT) scan and magnetic resonance imaging (MRI) showed a 23. 20. $30 \mathrm{~mm}$ sized, wellcircumscribed, mass which displaced the left adrenal gland anteromedially. The body bone scan found no active lesions.

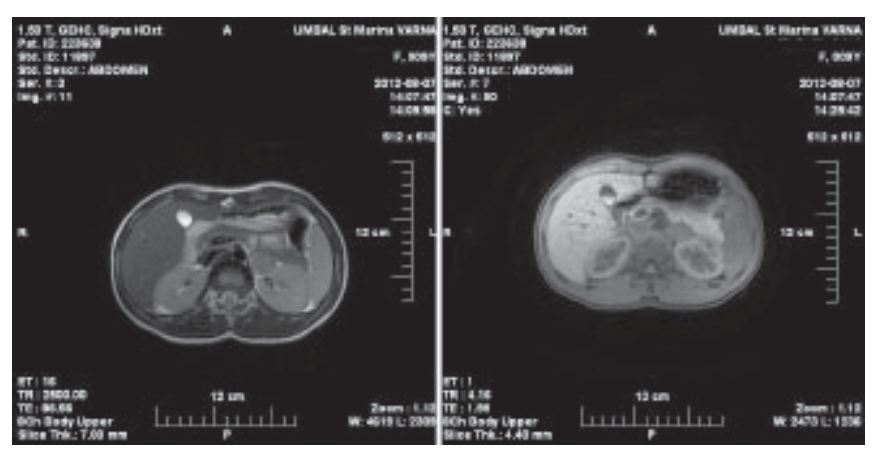

Fig. 1. MRI findings 


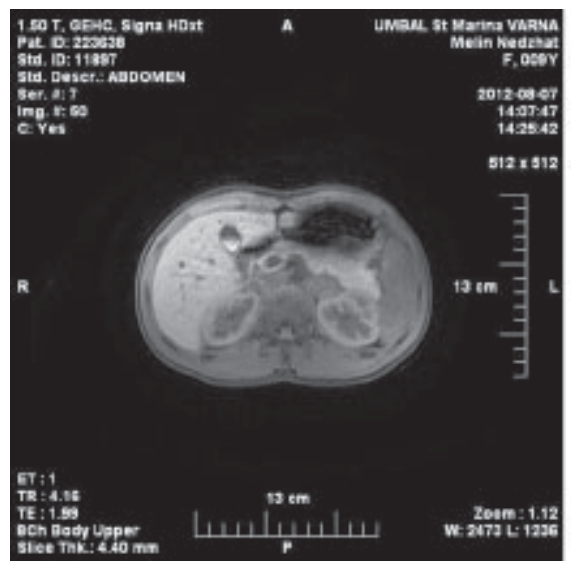

\section{SURGERY}

A laparoscopic left adrenalectomy was performed using the lateral transperitoneal approach. After putting the patient in anesthesia, she is placed in a sideways "jack-knife" position. Introduced are four trocar ports $1 \mathrm{~cm}$ subcostal along the medioclavicular line, anterior, medial and posterior axillary lines. The laparoscope is placed in the port on the anterior axillary line. The dissection is performed using an ultrasonic scalpel (Ultracision). Hemostasis is achieved by Ligasure, but ligation of vessels of over $3 \mathrm{~mm}$ metal clips are used. The left adrenal gland is reached after an incision along the line of Toldt from the lienal flexure to the colon sigmoideum. Dissection in this area provides access to the

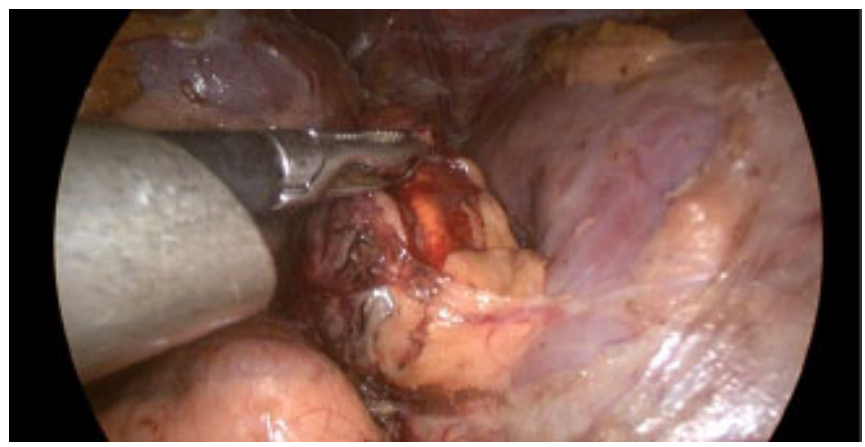

Fig. 3. Dissection of the tumor

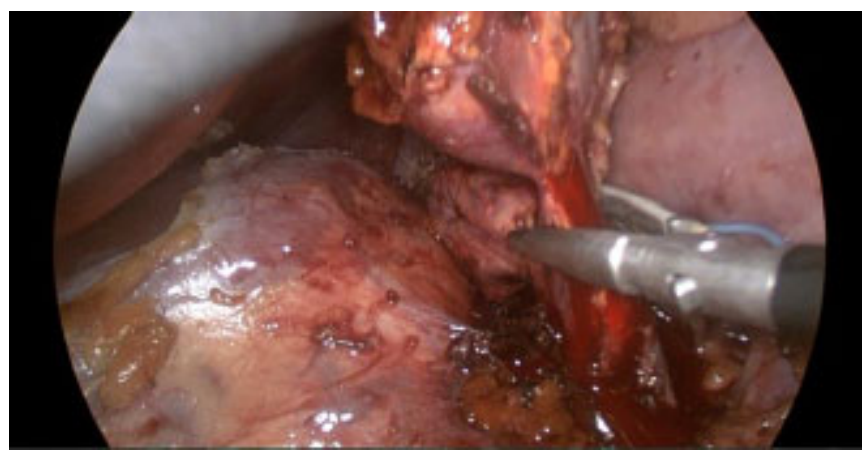

Fig. 5. Ligasure

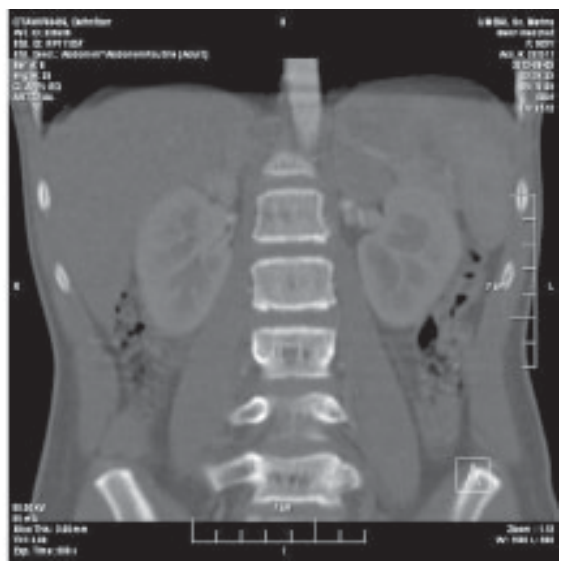

Fig. 2. CT findings

renal and adrenal veins. After control of the adrenal vein, an inferior dissection of the gland begins. After completing the inferior dissection, a medial dissection cranially of the renal vein is performed. The lateral dissection is performed in the plane between the renal cortex and the adipose tissue around the adrenal gland. After that follows a superior dissection of the gland, after which it is removed together with the adipose tissue and is removed from the abdominal cavity via an endobag.The mass was completely encapsulated and easily dissected from the superior pole of the left kidney. The resected tumor was encapsulated round mass, measuring $3 \times 2.8 \times 3.5 \mathrm{~cm}$ in dimension. The outer surface was smooth and glistening.

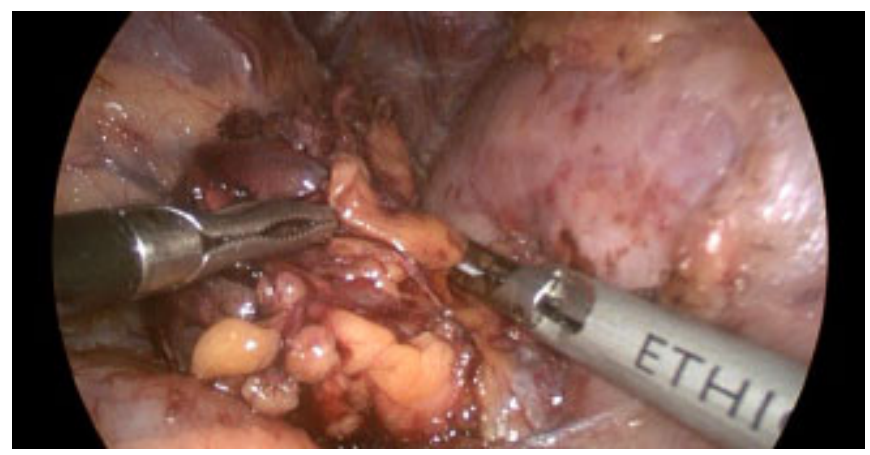

Fig. 4. Ulstrascision

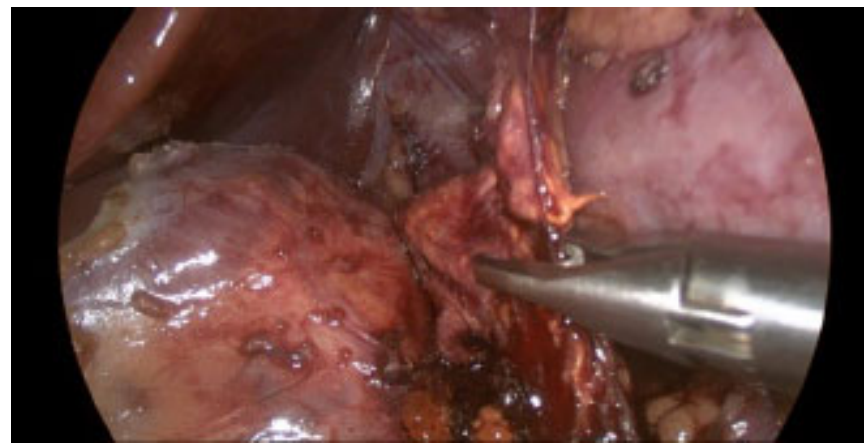

Fig. 6. Clipping 

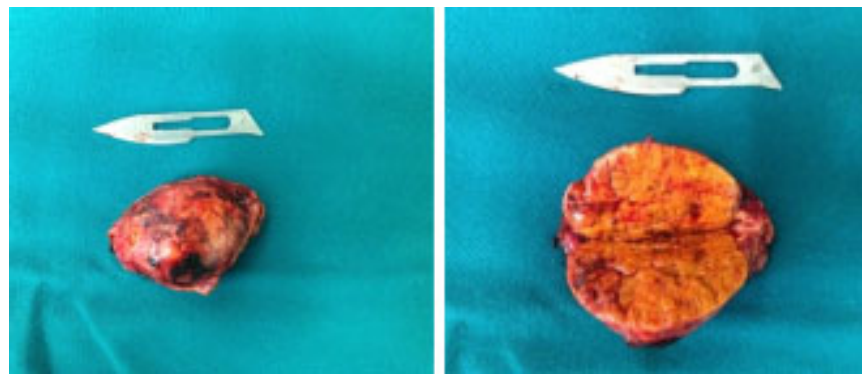

Fig. 7. Specimen

\section{MICROSCOPIC FINDINGS}

Microscopically, the tumor was solid well-demarcated with polygonal cells with abundant, eosinophilic, granular cytoplasm, rounded nuclei, some with mild atypia - one or more red nucleoli, anysokaryosis, anisochromasia, dual cells, low mitotic activity, multiple vascular slits. PTAH(-) IHH: Ae1/Ae3(-), synaptophysin(+), chromogranin(-), EMA(-), Ki67 $(<5 \%)$.Decisive for the diagnosis were the morphology of the tumor cells with eosinophilic, granular cytoplasm with a well-formed capsule. By IHH profile the most important are combination of synaptophysin+/ chromogranin-, and low mitotic activity - Ki67<5\% defined it as benign.

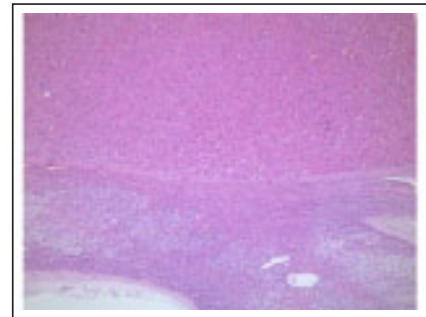

HE x40 (capsule)

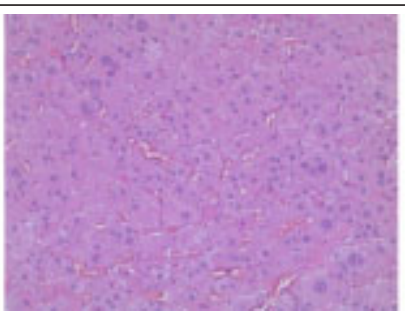

HE $\times 100$

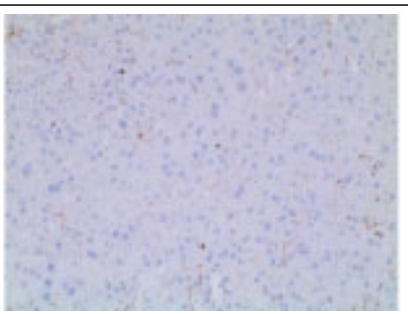

Ki67 x100

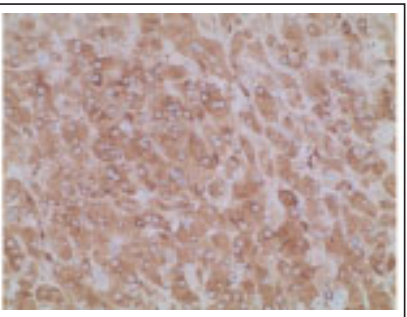

Synaptophysin x100

Fig. 8. Microscopic images

\section{AFTER SURGERY}

The post-operative recovery was uneventful.At 2 weeks after removal of the adrenal tumor, her serum testosterone, free testosterone and DHEA-S level decreased to normal ranges, respectively.

\section{DISCUSSION}

Adrenocortical neoplasms are rare in children. Tumors account for less than $0.2 \%$ of all pediatric neoplasms and $1.3 \%$ of all carcinomas in that age $[1,2]$. Adrenocortical tumors can be functional or non-functional. In children, most tumors are functional, with endocrine manifestations up to $90 \%$ [3]. Most of the children present with virilization due to excess androgen secretion.
The adrenocortical oncocytoma is extremely rare tumors. In children more often reported is oncocytoma of the kidney [4]. Only a few cases of adrenal oncocytoma have been reported in the literature [5]. They were usually benign and nonfunctioning. The functioning adrenocortical oncocytomas have been reported in only 3 pediatric patients [4-6].

\section{CONCLUSION}

In conclusion, we present a very rare case of virilizing adrenal oncocytoma in a child successfully laparoscopicaly treated. The malignant potential of this tumor is feeble and controversial. Nevertheless we must pay attention because little is known about the recurrence and biological characteristics of that tumor.

\section{REFERENCES:}

1. Chang A, Harawi SJ. Oncocytes, oncytosis and oncytotic tumors. Pathol Аппи. 1992; 27 Pt 1:263-304. [PubMed]

2. Hamperl H. Onkocytes and the so called hurthle cell tumor. Arch Pathol. 1950; 49:563-70.

3. Smirnova EA, Michailov IG. Electron microscopic characteristics of oncocytoma of the lung, small intestine and adrenal gland. [in Russian] Arkh Pathol. 1986; 48(6):79-81. [PubMed]

4. Lim YJ, Lee SM, Shin JH, Koh $\mathrm{HC}$, Lee YH. Virilizing adrenocortical oncocytoma in a child: a case report. $J$ Korean Med Sci. 2010 Jul;25(7):1077-9. Epub 2010 Jun 17. [PubMed] [CrossRef]

5. Tahar GT, Nejib KN, Sadok SS, Rachid LM. Adrenocortical oncocytoma: a case report and review of literature.J Pediatr Surg. 2008 May;43(5):E1-3. [PubMed] [CrossRef]

6. Gumy-Pause F, Bongiovanni M, Wildhaber B, Jenkins JJ, Chardot C, Ozsahin H. Adrenocortical oncocytoma in a child. Pediatr Blood Cancer. 2008 Mar;50(3):718-21. [PubMed] [CrossRef]

\section{Corresponding author:}

Anton Y. Tonev; University Hospital "St. Marina”, Medical University of Varna; 1, Hristo Smirnenski Blvr., Varna, Bulgaria.

E-mail: teraton@abv.bg; 